\title{
E-Government for human capability development program: An implementation of G2E System for enhanced government services
}

\author{
Ma. ELiza D. Mapanoo ${ }^{1,2, *}$, and Jonathan M. Caballero ${ }^{3}$ \\ ${ }^{1}$ Doctor in Information Technology, Technological Institute of the Philippines, Phillippines \\ ${ }^{2}$ University of Perpetual Help System - Laguna, Philippines \\ ${ }^{3}$ Technological Institute of the Philippines, Phillippines
}

\begin{abstract}
Government for human capability development program: an Implementation of G2E System for enhanced government services is design for Local Government Unit (LGU) which will enable every government employee to have an equal chance of providing services to their clientele and management. Philippines has been one of the countries promoting e-government where people linked to government agencies through the aid of network infrastructure, web technologies and database management. The system is designed and patterned to PRIME (Program to Institutionalize Meritocracy and Excellence in Human Resources Management) module, releases by Philippine Civil Service Commission which assures and safeguards smooth operations and procedures are done in every local government in both cities and municipalities. The system was test both in municipality and city to determine the readiness of its design and algorithm in handling government human resources management process. The design based on ISO 9126 yield a very good response from the respondents.
\end{abstract}

\section{Introduction}

Every nation dreamt of having a government where quality of services and equality to citizens are catered. Transformation of government to e-government and its services to egovernance has been a tremendous and continuous work of World Bank Organization [1] . As a result 103 out of 193 states member of United Nations participated in their survey "egovernment for Sustainable Development", which aims for determining who among members is still behind the transformation of ICT enable government that provide also egovernance[2].

In the latest survey done by [3] Philippines ranked 71 with an open standards datasets in 5 or more sectors, by region and having a High EGDI (e-Government Development Index) between 0.50 to 0.75 . The report also shows Telecommunication Infrastructure Index (.311), Human Capital Index (.71) and Online Service Component (.66).

Aiming for much better good governance, Philippine government launches Medium Term Information and Communications Technology Harmonization Initiative (MITHI), a

*Corresponding author: mapanoo.eliza@uphsl.edu.ph 
collaborative project of DBM (Department of Budget and Management), DOST (Department of Science Technology) and NEDA (National Development Authority) which aim to have a digitally - enabled, responsive and accessible government [4].

Envisioning Philippines as long-term collective vision and aspirations for Filipino people in the next 25 years, NEDA unveil AmbisyonNatin 2040. The program is composed of long term plan for a) Housing and Urban Development, b) Manufacturing, c) Connectivity, d) Education Services, e) Tourism and Allied Services, f) Agriculture, g) Health and Wellness Services, and h) Financial Services where 1) Filipino live a long and healthy life, 2) Filipino are smart and innovative and 3) Filipinos live in a high-trust society [5] . Philippine Development Plan (PDP) 2017 - 2022 is anchored to AmbisyonNatin 2040, this lay down a high trust and resilient society, a globally competitive knowledge economy which will serves the foundation of having an inclusive growth. This lay down the foundation of having an inclusive growth, a high trust and resilient society and a globally competitive knowledge economy [5].

World Bank Organization and UN survey reports, [6] shows that Philippine Government has a high index in terms of Citizen's access to government agencies and egovernment facilities but has a little index response to the citizen's query [2] In response, [5] included people centered, clean and efficient government in the Philippine Development Plan 2017 - 2022, which will enable citizens (a) to see transparency in every government agencies, (b) have seamless G2C, G2G, and G2B services and (c) strengthen the civil service program for public servant (NEDA, 2017). As a proof of transformation in government services, DILG, DICT and DOST conducted a survey which shows that out of 818 LGU Units, $58 \%$ of it are already implementing G2B through software eBPLS, and Tech4Ed for G2C (DOST, 2017). The report shows that G2E was left behind and needed to be established in order to strengthen government linkage to citizens via public servant institutionalize meritorious recognition. This can be done by the aid of development of eGovernment for Human Capability Development Program: An implementation of G2E System for Enhanced Government Services, which aims to (1) design a G2E application that will aid HRD in recruitment, selection and placement of qualified public servant and applicant using deep learning predictive analytics and (2) design a good profiling system for qualified applicants.

\section{Review of related literature}

e-Government is a one step platforms towards integrated public services which helps to connect individual system, public services and government functions into a one stop system enabling whole of government service in the delivery of economic, social and environmental areas [7].

e-Government was diversified into four (4) classifications: (a) Government to Business (G2B), (b) Government to Government (G2G), (c) Government to Employee and (d) Government to Citizen (G2C). This diversification shows a fundamental change in the whole public sector structure, values, culture and the ways of conducting business by utilizing the potential of ICT as a toll in the government agencies [8].

Local Government has been the focus of government in reaching citizens needs (G2C), reducing budget costs $(\mathrm{G} 2 \mathrm{G})$, saving time and increasing efficiency (G2B) and efficiency in providing services (G2E) [9].

With the aid of ICT e-Government continues to grow and meet the ever changing demand of citizens (Mohammed) . Enormous development of different e-government services from G2B, G2C, G2C define governance to e-governance with seal of transparency, bureaucracy and show quality within the work of every local and national government implementing it [10]. 


\subsection{Model of e-Government}

Perspective of defining e-government for e-governance varies from country to country, government agencies, citizen's preferences and needs.

[11] draw a guidelines for a stepwise transformation from e-governance solutions a personalized version. This will enable government to have a modelling technique in handling citizens relationship management.

A citizen centered oriented e-Government Maturity Model was presented by [12] which shows the four dimensions of a CRM: (1) organization, (2) services, (3) citizen's interaction and (4) citizens insight. The model make use of web presence survey to determine the maturity of services provided by the government to its citizens. Four factors are considered to test its maturity, this includes (1) ease of use, (2) system functionality, (3) system reliability and (4) system integration.

[13] believes that one of the successful factors for implementing e-government is to place all services in one citizen centered website where transactions can be made on a one stop basis. The model shows widely accepted maturity factors an e-government should have in order to create linkages to its citizen.

[14] compares twenty (25) e-government maturity models to find its similarities and differences, its weaknesses and strength in order to identify and classify where each model is suited to use. Models are Layne and Lee, Andersen and Henriksen, United Nation, Alhomod, Hiller and Belanger, Almazan and Gil-Garcia, CISCO, Gartner Group Open Government, West Maturity, Moon, World Bank, Deloitte and Touche, Howard, Shahkkoh, Lee and Kwak, Siau and Long, Wescott, Chandler and Emanuel, Kim and Grant, Chen, Windley, Reddick, Accenture, United Kingdom and Netchaeva Maturity Level. Results was based on the different e-Services taken by each author to identify its maturity level.

PeGI is an Indonesian eGovernment Ranking which evaluates the -government services in Indonesia. The model was divided into five (5) sections which determines the model capacity and credibility in handling Indonesian National Information Library, these are (1) Dimension Policy, (2) Institutional Dimensions, (3) Infrastructure Dimension, (4) Application Dimension and (5) Dimensional Planning. The model's survey resulted to good [15].

\subsection{Advantages of e-Government}

E-Government Maturity shows reduction on corruption and increases bureaucracy. The more the government is open and transparent to its citizen produces a good governance and sustainable environment to live [16].

[17] believes that a transparent smart e-Government with seamless access gives security and authentically flow of information crossing the interdepartmental barriers and providing unbiased service to the citizen.

[18] says that implementing E-HRM (1) saves time, (2) reduce cost, (3) decrease administrative burden, (4) facilitate HR Planning, and (5) allow HR Professionals to become strategic or business partners in organizations.

\section{Methodology}

\subsection{Proposed design framework}


The study make use of both descriptive and experimental method in order to determine the feasibility of the project and the quality of software developed for local government unit. The architectural design of the project are shown in Figure 1.

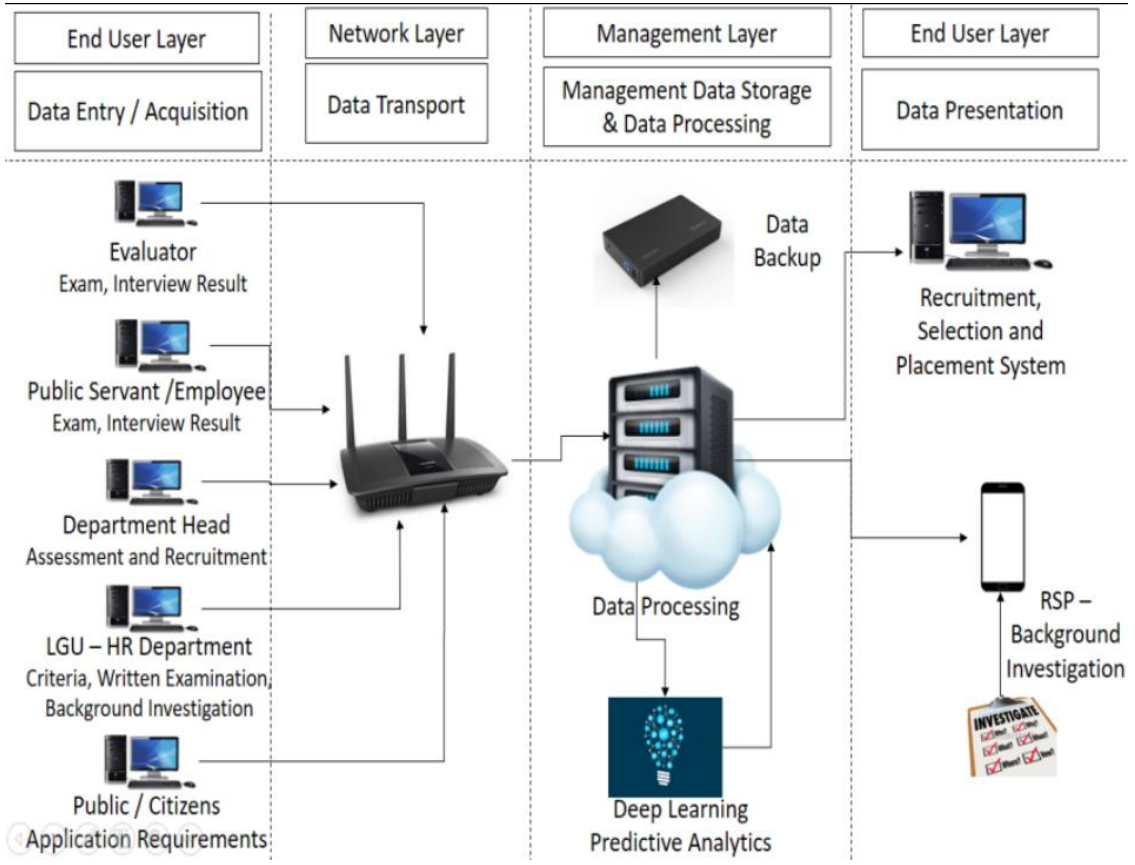

Fig. 1. G2E Architectural Design.

The system have four (4) level of end - users: (1) the evaluator, who is responsible for creating examination and encoding interview results, (2) the Public Servant, who is responsible for encoding his/her personal data sheet, (3) the Department head, who is responsible for requesting new public servant or accessing old public servant, (4) the HR Department, who is the main owner of the system and is responsible for giving / administering written examination and doing background investigation and (5) the public / society, this will allow individual to send requirements to the LGU for the vacant position publish over the internet. The data will be transport via wireless / wired connection through the main server connected to Centralized Repository.

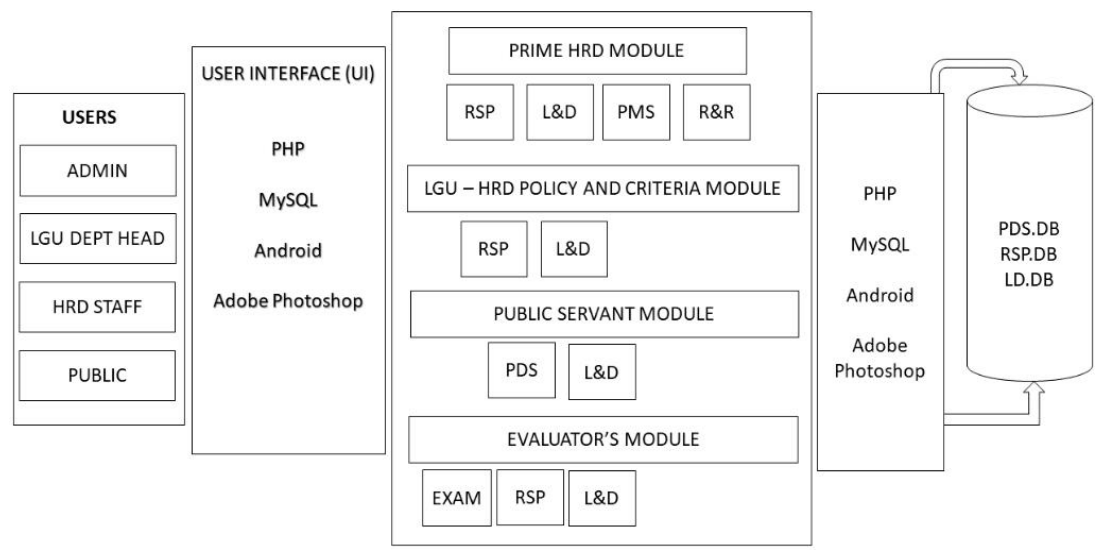

Fig. 2. G2E Application Design. 
Figure 2, illustrate the application design of e-Government for Human Capability Development Program: An Implementation of G2E System for Enhanced Government Services. The application will be used by LGU Department Head, HR Manager/Admin, HRD Staff, Public. The system will be developed using a PHP for system and SQL for handling the required database. Android will also be used for Successful Applicant's Background Investigation. Adobe Photoshop will be used for designing the system. The application was based on the PRIME Module from Civil Service Commission where policy and criteria in handling, mandating supervisory and non-supervisory services are stated. The LGU - HRD Policy and Criteria Module will be handled by the Administrator / HRD Manager; it will help the LGU - HRD unit to input all the criteria for (a) recruitment, selection and procurement, (b) Learning and Development, (c) Performance Management System, and (d) Rewards and Recognition. The Public Servant end - users are responsible for (a) entering their personal data sheet, (b) learning and development and (c) peer and self - evaluation. The evaluator's module is responsible for (a) entering examination to be given to aspiring applicant to an open position posted by the HRD Administrator, (b) enter score for the examination submitted by aspiring applicant in RSP, (c) input learning and development request for his/her subordinates, (d) view the respective L\&D attended by his/her subordinates, (e) evaluate public servant under his/her umbrella and (f) recommend and view the recognition and rewards his/her subordinates receives. The modules will be saved in a cloud storage or local host.

\subsection{Project respondents}

The study gathered data from the primary people who are currently connected with the LGU - HRD unit and has the capacity to explain the government proceedings, implementation, mandating and supervising public servant in doing government services. The study respondents are: (1) HR Manager, HRD Staff, Department Head, (2) Plantilla Public Servant, (3) Casual Public Servant and (4) Job Order Public Servant.

\subsection{Data collection method}

The researcher make use of interview, actual observation, questionnaire to determine the need and feasibility of the project. It was chosen the primary source of data. Respondents are identified and approached by the researcher to conduct interview. Actual observation and immersion to the LGU unit are done to fully understand the operation in providing services to LGU stakeholders, applicants and clients. Questionnaire was given before hand to the HR Manager and selected employees to determine requirements in creating the project. The results of the preliminary survey yield of wanting to have an automated system where transparencies can be seen.

\subsection{Testing and operating procedure}

As per requested by the LGU Department Head, there will be number of checking of the design prior to the development of project. Development of project will only took place, once the system design was already approved by the HR Staff and Manager. Alpha and Beta Testing should be also done to ensure smooth operation of project before installation and utilization of project will be done.

\subsection{Evaluation procedure}


The evaluation procedure is composed of three (3) stages:

1. Unit Checking - the unit checking is conducted periodically. Each module and unit of process that was included in the system came from the HR Department. Prototype was given two (2) weeks after the design was approved. This allow development team to refine the module/unit based on the end - user's requirements.

2. Preliminary Checking - all recommendations done in the unit checking are included in the design which form the unit testing or preliminary testing of project. To be able to determine the accurateness, reliability and effectiveness of the system design, the developer seek help from technical people such as HR manager of another government agency, staff from city and municipality government.

3. Final evaluation - survey instrument was distributed to the LGU Unit, to ensure the design's effectiveness, accuracy, understandability, and reliability of the design to conform the development of e-government for human capability program.

\subsection{Statistical tool}

The study used the statistical mean to interpret the result of the survey. Table 1 and 2 shows the numerical rating and descriptive rating of the mean to interpret of the project evaluation.

Table 1. Numerical Rating.

\begin{tabular}{|l|l|}
\hline Numerical Scale & Interpretation \\
\hline 5 & Excellent \\
\hline 4 & Very Good \\
\hline 3 & Good \\
\hline 2 & Fair \\
\hline 1 & Poor \\
\hline
\end{tabular}

Table 3 shows the numerical rating used in the questionnaire in order to determine the usefulness of the system. It is rated with five (5) having an excellent rating and one (1) as its lowest rating.

Table 2. Likert Scale.

\begin{tabular}{|l|l|}
\hline Numerical Scale & Interpretation \\
\hline $4.51-5.00$ & Excellent \\
\hline $3.51-4.50$ & Very Good \\
\hline $2.51-3.50$ & Good \\
\hline $1.51-2.50$ & Fair \\
\hline $1.00-1.50$ & Poor \\
\hline
\end{tabular}

The evaluated results were interpreted based on the mean that scores that gathered from the selected evaluators corresponding to LGU Heads and LGU employees.

\section{Results and discussion}

This section presents the results as well as the discussion gathered from the final design evaluation.

\subsection{Project design evaluation}

The project design evaluation was conducted through the use of survey instrument. Table 5, shows the summary of evaluation done by the LGU Head and selected employees. 
Table 5. Summary of Software Evaluation Overall Mean Scores.

\begin{tabular}{|c|c|c|}
\hline Indicators & Over All Mean & $\begin{array}{c}\text { Verbal } \\
\text { Interpretation }\end{array}$ \\
\hline Functionality & 4.57 & Excellent \\
\hline Reliability & 3.58 & Very Good \\
\hline Usability & 3.64 & Very Good \\
\hline Efficiency & 3.60 & Very Good \\
\hline Maintainability & 3.60 & Very Good \\
\hline Portability & 3.62 & Very Good \\
\hline Over All Mean & $\mathbf{3 . 7 8}$ & Very Good \\
\hline
\end{tabular}

Based on preliminary testing done in Local Government Units the results are as follows:

(1) For HR Technical Preliminary Checking - the system was checked and test against the Civil Service Commission module for Recruitment, Selection and Management. It then comply with objective 1 and 2, the development of G2E application that will aid HR Department in recruitment, selection and placement for qualified pubic servant and applicant. Based on the rating done by the HR Manager, the system yield a Very Good Rating.

(2) For IT Technical Preliminary Checking - the system was checked and test based on the specification of each Local Government Unit ICT's setup. IT Staff and Officer determine the attainment of objective 1 in producing qualified and non - qualified employee and applicant. Testing of algorithm used in the system will be scheduled once additional modules was injected in the website. The system also yield a good rating. Leaving the database migration and adaptation as a Predictive Analytics deficiency.

(3) For LGU end - user Preliminary Checking - the system was checked based on their functions, role and usage in the system. Table 2, show the Overall mean of system evaluation.

The Overall mean score for preliminary testing is 3.78 which is equivalent to very good rating.

Functionality got the highest rating. This attest that the system can run on different platform and environment. It proves that the system can give the precise data in identifying qualified and non - qualified applicant and employee for every vacant position requested.

Portability got a rating of 3.62, this means that the system can be easily access by endusers. Access in the system is based on their role and function given by the administrator.

Reliability comes next, since the components of HR System are seen in the system. This quality shows that the system produces correct, accurate and reliable results of determining the qualified applicant, as well as the automatic computation of grades encoded by the evaluator. Background investigation encoded by the HR staff are automatically seen by the evaluator.

The System was evaluated by 100 end - user, 2 HR Manager and 2 IT Head.

\section{Conclusion}

This section present the summary of findings, conclusions and recommendations of the study.

\subsection{Summary of findings}


e-Government for Human Capability Development Program: An implementation of G2E System for Enhanced Government Services is a system that will shows equality and equity to local government unit employee in terms of (1) applying for higher position, (2) giving rewards and recognition, (3) grant to attend leadership and development seminar and (4) equal distribution of workload. It is divided into four(4) modules: (1) Recruitment, Selection and Placement, (2) Leadership and Development, (3) Rewards and Recognition and (4) Performance Management System. None conformance to the first three modules would yield a non - data for Performance Management System.

Based on the result of evaluation conducted, the following are the summary of the findings of the study:

1. Functionality. It is rated excellence because all the modules carries all the forms required by the LGU Unit. The design is easy to understand and well explained. It will shows comfort and convenience once it is developed and implemented.

2. Reliability. It is rated very good because it conforms to the desired design result, provide security and it is complete based on the given requirements by the stakeholders.

3. Usability. It is rated very good because the design of the system is reusable in the near future. It include module where HR unit can change ranking percentage.

4. Efficiency. It is rated very good because the design shows availability of needed reports and data to be submitted to civil service commission.

5. Portability. It is rated very good since the design where it will be implemented is flexible.

\subsection{Conclusions}

In consideration of the objective of the study and the result of the evaluation, the following conclusions where drawn:

1. That the system is functional and usable in the LGU unit as part of G2E. Elements, contents and parameters set by the LGU and Civil Service Commissions are all seen in the design. The HR Manager believes that when the system is fully developed and implemented within the LGU Unit will show transparency in promoting, enhancing and elevating and recognizing government employees skills, talent and knowledge.

2. That the system based on the evaluation made by the pilot LGU unit and to another LGU government agency which also caters the same procedures has passed the capacity of rendering transparency in giving meritorious recognition and award among government employees once it is implemented.

3. That the system was checked and improved based on the suggestions and recommendations made by the stakeholders.

\subsection{Recommendations}

The following are recommendation for further enhancement of the system design.

1. Aside from catering municipalities only, cities should be included in the system development.

2. The system design should include database migration in its design.

\section{References}

1. Melhem, Samia. "Burkina Faso's digital ambition: transforming through eGovernment and digital platforms." 12 Jan 2017. The World Bank. $<$ https://blogs.worldbank.org/category/tags/egovernment $>$. 
2. DESA, UN. UN e-Government Survey. New York: United Nation, (2016).

3. UN-DESA. e-Government in Support of Sustainable Development. New York: United Nations Public Administration, (2016).

4. iGov-Philippines. "e-Government Master Plan and the Integrated Government Philippines Project." (2016).

5. NEDA. AMBISYON 2040. 2016. <http://2040.neda.gov.ph/about-ambisyon-natin2040/>. _. "Philippine Development Plan 2017 - 2022." (2017).

6. WBG. "Digital Dividends." (2016).

7. Louis, Raphael. "What Leaders Should Know about e-Government." SocioEconomic Challenges 1.23 (2017): 73-78.

8. Alshehri, Mohammed, Drew, Steve, Alfarraj, Osama. "A Comprehensive Analysis of E-government services adoption in Saudi Arabia: Obstacles and Challenges." International Journal of Advanced Computer and Applications (2012).

9. Drew, S., Alshehri, M. "Implementation of e-Govenment: Advantages and Challenges." IASK International Conference E-Activity and Leading Technologies and InterTic 2010. (2010).

10. Tinholt, D.,Linden, N., Groeneveld, N. "eGovernment Benchmark 2017: Raking Stock of user-centered design and delivery of digital public service in Europe." (2017).

11. Zakaria, M.R. "Personalized E-Government System: Towards an Adaptive Maturity Model." International Journal of Business Research and Development (2014): 1-7.

12. Wulansari, A., Subriadi, Apol P.,. "Developing Citizen Relationship Management (CiRM) Oriented E-Government Maturity Model." IPTEK, Journal of Engineering (2017): 22-28.

12. Nabafu, R., Maiga, G. "A Model Success Factors for Implementing Local eGovernment in Uganda." Electronic Journal of e-Government (2012): 31-46.

13. Fath-Allah, A., Cheikhi, L., Al-Qutaish, R.E., Idri, A. "e-Government Maturity Models: A Comparative Study." International Journal of Software Engineering and Applications (2014): 71-91.

14. Sensuse, D. I., Nasbey, A., Nordianto, Dewiyanti, R., Novira, R., Dzulfikari, M. "PeGI in Practice: The eGovernment Assessment in National Library of Indonesia." (2017).

15. Krishnan, S., Teo, T.S.H., Lim, V.,. "e-Government Maturity, Corruption and Ecoefficiency." Pacific Asia Conference on Information System. Asiel.aisnet.org, (2012). $1-18$.

16. Bhukya, S., Pabboju, Dr. S. "Software Architecture Techniques and Emergence of Problem Domain in E-Governance." International Conference on Electrical, Electronics, and Optimization Techniques . IEEE, (2016).

17. Aghafri, Abdul A. "Literature Review On: The Advantages and Disadvantages of Implementing E-HRM for an Oganisation, E-Learning as an Example." American Journal of Economics (2015): 51-55. 